\title{
Improvement of Stability of Rotor System by Introducing a Hydraulic Damper into an Active Journal Bearing
}

\author{
J. M. KRODKIEWSKI ${ }^{\mathrm{a}, *}$, Y. CEN, ${ }^{\mathrm{b}}$ and L. SUN ${ }^{\mathrm{c}}$
}

${ }^{a}$ Department of Mechanical and Manufacturing Engineering, The University of Melbourne, Melbourne, Victoria 3052, Australia; ${ }^{\mathrm{b}}$ East China Institute of Metallurgy, Maanshan, Anhui 243002. P. R. China; ${ }^{\mathrm{c}}$ Department of Mechanical and Manufacturing Engineering, The University of Melbourne, Melbourne, Victoria 3052, Australia

(Received 8 April 1996; In final form 8 April 1996)

\begin{abstract}
Modelling and analysis of a rotor-bearing system with a new type of active oil bearing is presented. The active bearing is supplied with a flexible sleeve whose deformation can be changed during operation of the rotor. The flexible sleeve is also a part of a hydraulic damper whose parameters can be controlled during operation as well.

Finite Element Method (FEM) and the Guyan condensation technique was utilised to create mathematical model of both, the rotor and the flexible sleeve. The hydrodynamic pressure distribution in the oil film, for the instantaneous position of the flexible sleeve and rotor, was approximated by Reynolds equation.

The mathematical model of motion of a rotor system with the described active bearing developed in this paper allowed the influence of the introduced hydraulic damper on stability of the rotor-bearing system to be investigated. Results of the computer simulation shows that within a large region of configuration parameters of the rotor bearing system, the self exciting vibration can be eliminated or greatly reduced during operation by properly controlled deformation of the flexible sleeve and optimal choice of the hydraulic damper parameters.
\end{abstract}

Keywords: Oil Bearings, Active Control, Rotor System, Stability, Modelling, Analysis

\section{INTRODUCTION}

A multi-bearing rotor system is statically indeterminate. Its dynamic behaviour depends on the relative positions of the bearings as well as properties of its subsystems. The relative positions of the bearings are usually referred to as the system configuration, or bearing alignment (Parszewski Krodkiewski [1986]). Therefore, the dynamic properties of the multi-bearing rotor system are a function of the rotating speed and the system configuration. Consequently, the investigation of the dynamic behaviour of the rotor system can be undertaken in two domains. One is in the rotating speed domain, the other is in the configuration domain.

*Corresponding author. Tel.: 61-3-344-7242. Fax: 61-3-344-8784. E-mail: jmk@sungear.mame.mu.oz.au. 
Self-excited vibration (oil whip), is one of the main causes of severe rotor vibration. Great efforts have been made on the analysis and improvement of the stability of rotor systems. Lund [1974] calculated the threshold speed and the damped critical speeds of a flexible rotor in journal bearings using a linearised model of the bearing. Adams [1980] used a non-linear model to simulate the response of a multi-bearing rotor system to study the instability threshold speed. Holmes et al. [1978] studied the self-excited vibration of a two-rotor four-bearing system due to vertical misalignment of the bearings. The effect of bearing alignment on the stability boundary has been studied by Hori and Uematsu [1980]. Parszewski and Li [1989] presented a method to obtain the optimal configuration of a multi-bearing rotor system with respect to the forced vibration.

The system configuration may change during operation due to the thermal expansion, deformation of the supporting structures, etc. The change affects the dynamic response of the rotor system and in many cases its improvement is necessary during operation. Therefore, the active vibration control has been paid growing attention in the dynamic design of the rotating machinery. The design of active oil bearings could be divided into two categories. The first design is based on actively changing the properties of the oil film. It can be done either by pumping the oil or air with different pressure into the oil film (Goodwin et al. [1989]) or by altering the thickness and geometry of the oil film. Another design includes movable elements (ring or pads). The motion of these elements is activated either by hydraulic systems (Ulbrich and

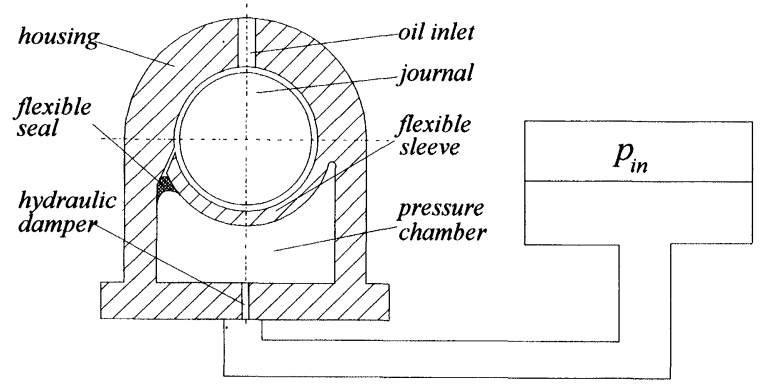

FIGURE 1 Schematic of the active bearing.
Althaus [1989]) or by piezoelectric pushers (Adams and McCloskey [1990]). The change of the characteristics of the rotor system is achieved by applying control forces (normally by a feed back loop) to the rotor via the oil film. The active tilting pad bearing can be used in both of the above designs.

In this paper the influence of modification of the active bearing described by Krodkiewski and Sun [1995] is investigated. To improve attenuation of vibrations of a rotor bearing system the active bearing was supplied with a hydraulic damper.

\section{DESCRIPTION OF THE ACTIVE BEARING}

The flexible sleeve (see Fig. 1) can be considered as a new feature of the proposed bearing. The oil film and the pressure chamber are separated by the flexible sealing. Equilibrium position of the flexible sleeve and the bearing journal is determined by the bearing load and the pressure $p_{\text {in }}$ which can be controlled during operation. Vibration of the flexible sleeve around its equilibrium position causes flow of the chamber oil through the hydraulic damper. Parameters of this damper can be also varied during operation. If the inlet pressure $p_{\text {in }}$ and parameters of the damper are function of the system configuration or its rotating speed, the bearing can be considered as adaptive one. Search for their optimal values is the main purpose of this paper.

\section{MODELLING OF THE ROTOR-ACTIVE BEARING SYSTEMS}

\section{Modelling of The Rotor And The Flexible Sleeve}

The physical model of a three-bearing rotor system is shown in Fig. 2. The active bearing is located in the middle of the rotor. The rotor was approximated by the two degrees of freedom system with concentrated mass at the location of the active bearing. Its instantaneous position $O_{r}$ with respect to the absolute sys- 

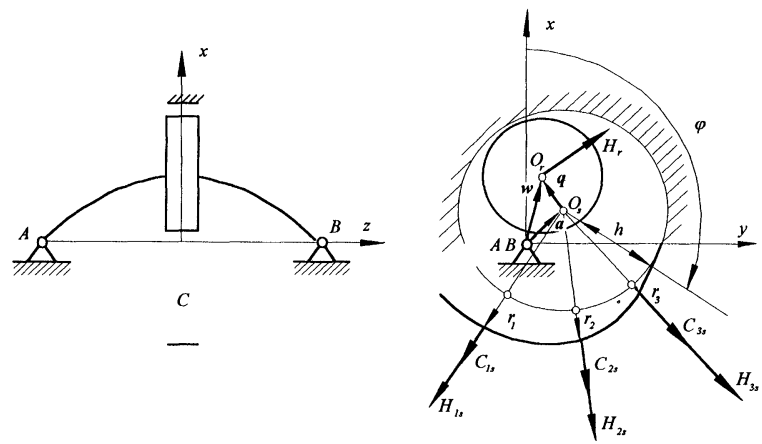

FIGURE 2 The physical model of the rotor.

tem of coordinates $x y z$ is determined by vector $\boldsymbol{w}$. Configuration of the rotor bearing system (the relative position of its bearings) is defined by vector $\boldsymbol{a}$. The mathematical model of the rotor was adopted in the following form:

$$
M_{r} \ddot{w}+K_{r} w=H_{r}(q, \dot{q}, r, \dot{r})+Q_{r}+F_{r}
$$

The Guyan condensation technique was used to produce the inertia $\boldsymbol{M}_{\boldsymbol{r}}$ and stiffness $\boldsymbol{K}_{\boldsymbol{r}}$ matrices. The hydrodynamic force that acts on the journal is denoted by $\boldsymbol{H}_{\boldsymbol{r}}$ while $\boldsymbol{Q}_{\boldsymbol{r}}$ and $\boldsymbol{F}_{\boldsymbol{r}}$ stand for vector of the gravity forces and the external excitation respectively. Since:

$$
w=a+q
$$

where $\boldsymbol{q}$ represents the relative motion of the journal with respect to the bearing, the equation of motion of the rotor takes the following form:

$$
M_{r} \ddot{q}+K_{r} q=H_{r}(q, \dot{q}, r, \dot{r})-K_{r} a+Q_{r}+F_{r}
$$

The flexible sleeve was modelled as a curved beam and its dynamic properties (the mass matrix $\boldsymbol{M}_{\boldsymbol{s}}$ and the stiffness matrix $\boldsymbol{K}_{\boldsymbol{s}}$ ) were determined along coordinates $r$ (see Fig. 2.) by means of FEM and the Guyan condensation technique. Its motion can be approximated by the equation below.

$$
M_{s} \ddot{r}+K_{s} r=H_{s}(q, \dot{q}, r, \dot{r})+C_{s}
$$

In the equation (4) $\boldsymbol{H}_{s}$ stands for vector of the hydrodynamic force caused by oil film pressure $p$ and $C_{s}$ stands for vector of the hydrodynamic forces caused by pressure in the control chamber $p_{c}$. Both of them were computed from the instantaneous pressure distribution by means of the virtual work principle. Distribution of the oil film pressure $p$ was modelled by means of the Raynolds equations.

$$
\frac{1}{R^{2}} \frac{\partial}{\partial \varphi}\left(\frac{h^{3}}{\eta} \frac{\partial p}{\partial \varphi}\right)+\frac{\partial}{\partial z}\left(\frac{h^{3}}{\eta} \frac{\partial p}{\partial z}\right)=6 \Omega \frac{\partial h}{\partial \varphi}+12 \frac{\partial h}{\partial t}
$$

More details on modelling of the rotor and the flexible sleeve can be found in work by Krodkiewski and Sun [1995]. The chamber pressure $p_{c}$ depends upon the inlet pressure $p_{\text {in }}$ (see Fig. 1), parameters of the hydraulic damper and motion of the flexible sleeve $r$.

\section{Modelling of The Chamber Pressure}

If the initial volume of the chamber is denoted by $V_{o}$ (see Fig. 3) and the fluctuation of this volume due to motion of the flexible sleeve by $\Delta V$, the instantaneous volume can be expressed as follows:

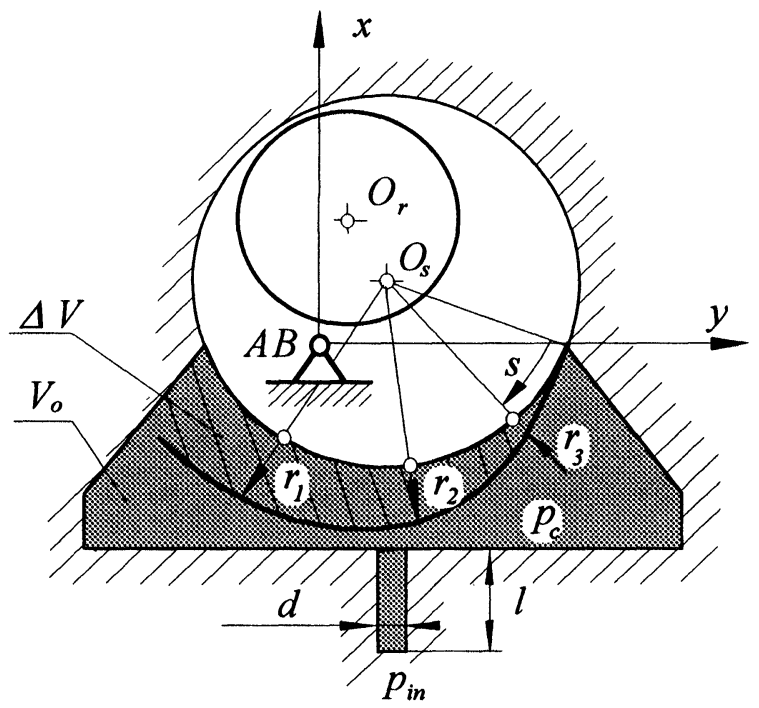

FIGURE 3 The physical model of the chamber. 


$$
V=V_{o}-\Delta V
$$

where

$$
\Delta V=W_{s} \int_{0}^{L_{s}} r(s) d s
$$

Length and width of the flexible sleeve in the last equation are denoted by $L_{s}$ and $W_{s}$ respectively.

Rate of change of volume of oil $V_{c}$, due to its compressibility, can be determined by the following equation:

$$
\frac{d V_{c}}{d t}=-\frac{V}{B} \frac{d p_{c}}{d t}
$$

where $B$ is the bulk modulus of oil.

To fulfil the continuity of flow requirements, the rate of change of the oil flow through the damper has to obey the following formula:

$$
Q=\frac{d \Delta V}{d t}+\frac{d V_{c}}{d t}
$$

On the other hand, the rate of flow through the damper is determined by its diameter $d$, length $l$ and the inlet pressure $p_{\text {in }}$ and chamber $p_{c}$ pressure

$$
Q=\frac{\pi d^{4}}{128 \eta l}\left(p_{c}-p_{i n}\right)
$$

Equations (10), (9) and (8) allow to develop the relationship between motion of the flexible sleeve and the chamber pressure.

$$
\frac{d p_{c}}{d t}=k_{1}\left(k_{2}\left(p_{\text {in }}-p_{c}\right)+\frac{d \Delta V}{d t}\right)
$$

where:

$$
k_{1}=\frac{B}{V} \quad k_{2}=\frac{\pi d^{4}}{128 \eta l} .
$$

The equation (11) governs correctly the chamber pressure if its magnitude is greater than the cavitation threshold $p_{c a v}$. If during integration of the system equations of motion the chamber pressure dropped below this threshold value, the adopted for computation pressure was equal to $p_{c a v}$ (see Fig. 4). The chamber pressure was kept equal to $p_{c a v}$ as long as the expression (13) was greater than zero.

$$
\begin{gathered}
V_{B}=\left(W_{s} \int_{0}^{L_{s}} r(s, t) d s-W_{s} \int_{0}^{L_{s}} r\left(s, t_{i}\right) d s\right)- \\
k_{2}\left(p_{\text {in }}+p_{c a v}\right)\left(t-t_{i}\right)>0 .
\end{gathered}
$$

The above expression represents part of volume of chamber filled by vapour of oil due to the cavitation process.

\section{NUMERICAL SOLUTION OF THE MATHEMATICAL MODEL AND ITS PARAMETERS}

The equations (3) and (4) form simultaneous set of five differential equations

$$
\begin{gathered}
\boldsymbol{M}_{\boldsymbol{r}} \ddot{\boldsymbol{q}}+\boldsymbol{K}_{\boldsymbol{r}} \boldsymbol{q}=\boldsymbol{H}_{\boldsymbol{r}}(\boldsymbol{q}, \dot{\boldsymbol{q}}, \boldsymbol{r}, \dot{\boldsymbol{r}})-\boldsymbol{K}_{\boldsymbol{r}} \boldsymbol{a}+\boldsymbol{Q}_{\boldsymbol{r}}+\boldsymbol{F}_{\boldsymbol{r}} \\
\boldsymbol{M}_{s} \ddot{\boldsymbol{r}}+\boldsymbol{K}_{s} \boldsymbol{r}=\boldsymbol{H}_{s}(\boldsymbol{q}, \dot{\boldsymbol{q}}, \boldsymbol{r}, \dot{\boldsymbol{r}})+\boldsymbol{C}_{s} \\
\boldsymbol{q}=[x, y]^{T} \boldsymbol{H} \boldsymbol{r}=\left[r_{1}, r_{2}, r_{3}\right]^{T}
\end{gathered}
$$

These equations were solved by means of the Runge Kutta method. The necessary pressure distributions

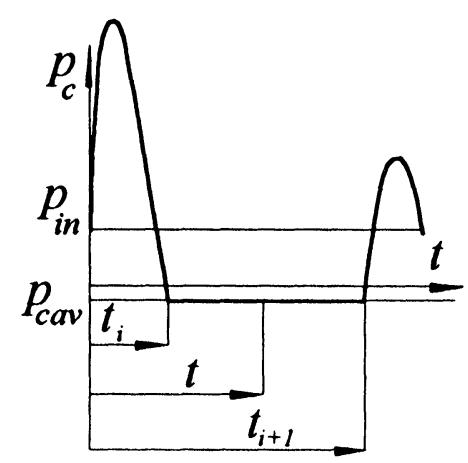

FIGURE 4 Chamber pressure as a function of time due to the cavitation process. 
TABLE I Parameters of the Rotor Bearing System.

\begin{tabular}{|c|c|c|c|c|c|}
\hline$m$ & $\omega_{l}$ & $S$ & $D$ & $L / D$ & $c$ \\
\hline $11.24 \mathrm{~kg}$ & $8.95 \mathrm{~Hz}$ & $1.7 \mathrm{~m}$ & $0.05 \mathrm{~m}$ & 0.8 & $0.0003 \mathrm{~m}$ \\
\hline$\beta$ & $\psi$ & $\eta$ & $\Omega$ & $a_{x} a_{y}$ & $p_{\text {in }}$ \\
\hline $105^{\circ}$ & $160^{\circ}$ & $0.04 \mathrm{~Pa} \mathrm{~s}$ & 3000 RPM & $-1.85,0 \mathrm{~mm}$ & $0.1 \mathrm{MPa}$ \\
\hline$p_{\text {cav }}$ & $b$ & $k_{i}$ & $k_{2}$ & & \\
\hline$-0.03 \mathrm{MPa}$ & $4 \cdot 10^{-3} \mathrm{~m}$ & $10^{11} \mathrm{~Pa} \mathrm{~m}^{-3}$ & $3 \cdot 10^{11} \mathrm{~N}^{-1} \mathrm{~m}^{5} \mathrm{~s}^{-1}$ & & \\
\hline
\end{tabular}

inside the oil film as well as pressure in the chamber, at each step of integration, were computed from equations (5) and (11). Integration of the pressure along surface of the flexible sleeve and journal yields the hydrodynamic forces $\boldsymbol{H}_{\boldsymbol{r}}, \boldsymbol{H}_{s}$ and $\boldsymbol{C}_{s}$.

Parameters of the physical model of the rotor bearing system adopted for the numerical analysis are collected in Table I.

The listed in Table I parameters correspond to an existing rotor-bearing system. The following numerical simulation of motion of the rotor system was aimed to obtain optimal parameters of the hydraulic damper.

\section{RESULTS OF THE NUMERICAL COMPUTATION}

Influence of the following parameters on improvement of stability of the rotor system response was investigated:

1. bulk modulus $B\left(k_{l}\right)$

2. length $l$ and diameter $d$ of the damper capillary (coefficient $k_{2}$ )

3. thickness of the flexible sleeve $b$.
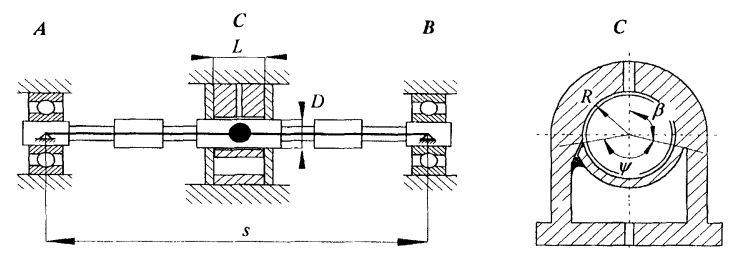

FIGURE 5 Schematic of the rotor system.
The following diagrams present displacement of the journal along $x$ direction and displacement of the flexible sleeve along coordinate $r_{l}$ (see Fig. 2) in dimensionless form as a function of time.

\section{Influence of Bulk Modulus $\left(k_{l}\right)$}

The bulk modulus of the oil depends on quantity of the air mixed with the oil and its magnitude is usually less than $2 \cdot 10^{9} \mathrm{~Pa}$. With increasing amount of air, magnitude of the bulk becomes smaller and smaller amount of oil flows through the damper capillary. Therefore smaller value of the bulk modulus results in poorer improvement of stability of the system equilibrium position. Some results of the numerical simulation, for three different magnitudes of the bulk modulus $\left(B=10^{6}, 10^{7}, 10^{8} \mathrm{~Pa}\right)$ and the chamber volume $V=10^{-4} \mathrm{~m}^{3}$, are shown in Fig. 6 .

For small magnitude of the bulk modulus $B$ (Fig. 6.a), the journal and the flexible sleeve move along large limit cycles. Increment in $B$ (see Fig. 6.b) re-
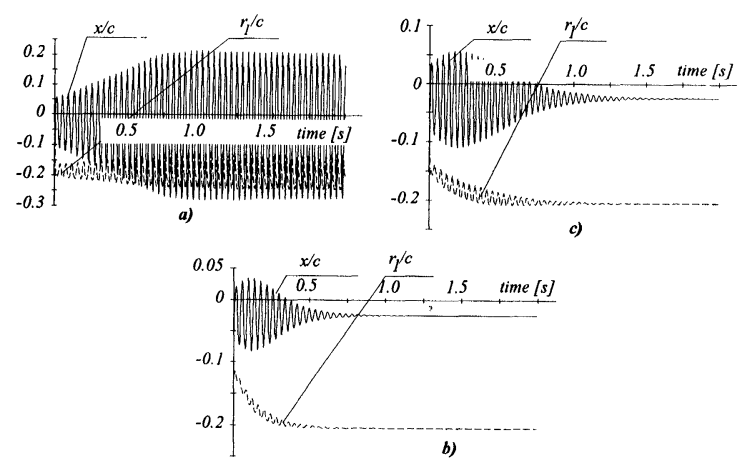

FIGURE 6 Influence of the bulk modulus; a) $k_{1}=10^{10}\left[\mathrm{Nm}^{-5}\right]$, b) $k_{l}=10^{11}\left[\mathrm{Nm}^{-5}\right]$, c) $k_{l}=10^{12}\left[\mathrm{Nm}^{-5}\right]$. 
sults in stabilisation of the equilibrium position. Further increment of value of the bulk modulus (see Fig. 6.c) insignificantly improves stability of the equilibrium position.

\section{Influence of Damper Parameters}

The hydraulic damper properties are determined by its diameter and length (see formula (12)). The computer simulation indicates that for any working parameters of the rotor system there exists an optimal set of the damper parameters determined by the coefficient $k_{2}$. Sample of this computation is shown in Fig. 7.

If the bearing is not supplied with the damper (Fig. 7a), its journal as well as its sleeve perform large self exciting vibrations along a limit cycle around the unstable equilibrium position. For $k_{2}=1 \cdot 10^{-12}\left[\mathrm{~N}^{-1}\right.$ $\left.m^{5} s^{-1}\right]$ (Fig. 7b) the equilibrium position is still unstable but the dimensionless peak to peak amplitude of the journal limit cycle is as small as 0.09. Case $k_{2}$ $=3 \cdot 10^{-11}\left[\mathrm{~N}^{-1} \mathrm{~m}^{5} \mathrm{~s}^{-1}\right]$ (Fig. 7c) seems to be optimal. As can be seen, in this case the equilibrium position is stable. Further increment in the coefficient $k_{2}$ to $3 \cdot 10^{-10}\left[\mathrm{~N}^{-1} \mathrm{~m}^{5} \mathrm{~s}^{-1}\right]$ (see Fig. $7 \mathrm{~d}$ )) results in the unstable equilibrium position.
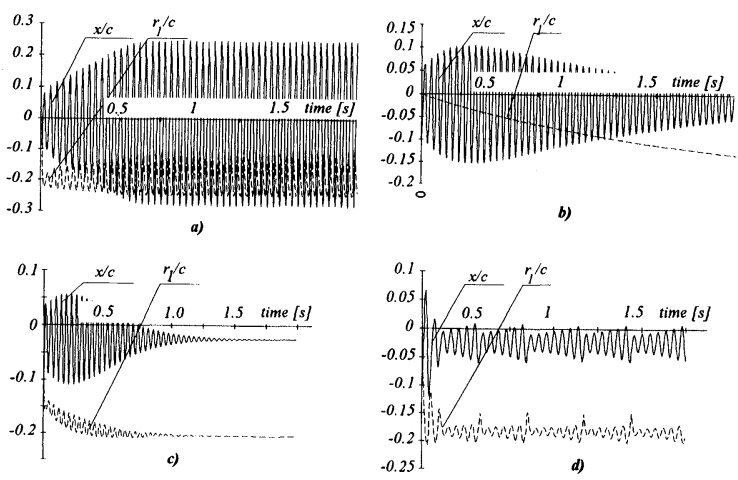

FIGURE 7 Influence of the throttling parameter $k_{2} ;$ a) $k_{2}=\infty(p$ $=$ constant $)$, b) $\left.k_{2}=1 \cdot 10^{-12}\left[\mathrm{~N}^{-1} \mathrm{~m}^{5} \mathrm{~s}^{-1}\right], \mathrm{c}\right) k_{2}=3 \cdot 10^{-11}\left[\mathrm{~N}^{-1}\right.$ $\left.m^{5} s^{-1}\right]$, d) $k_{2}=3 \cdot 10^{-10}\left[N^{-1} m^{5} s^{-1}\right]$.

\section{Influence of Thickness of The Flexible Sleeve}

The described above simulation was carried out for different thickness of the flexible sleeve $b$ and for different magnitudes of coefficient $k_{2}$. For any combination of these parameters the peak to peak amplitude of limit cycle $A$ was recorded. Its dimensionless magnitudes $A / c$ as a function of the dimensionless thickness $b / R$ and the coefficient $k_{2}$ are presented in Fig. 8 .

As one can see from Figure 8, thinner sleeve results in wider range of stability.

\section{CONCLUSIONS}

The presented numerical computation indicates that stability of the equilibrium position of rotor-oil bearing system can be significantly improved by means of the proposed active bearing with the hydraulic damper.

Since the optimal parameters depend on the system current configuration and rotating speed, the diameter of the capillary as well as the inlet pressure has to be controlled during operation.

To reduce influence of the ever existing compressibility of oil which is reflect by the bulk modulus, volume of the chamber should be as small as possible.

To reduce the influence of cavitation, the inlet pressure should be possibly high. Hence in case of heavily loaded bearings the proposed hydraulic damper is more effective. In case of lightly loaded bearings a compromise should be sought between the thickness of the sleeve and the inlet pressure.

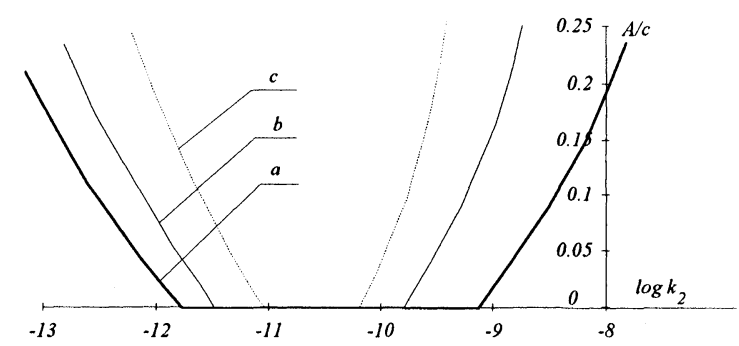

FIGURE 8 The peak to peak amplitude of limit cycle as a function of the throttling coefficient; a) for $b / R=0.12$, b) for $b / R=$ $0.16, \mathrm{c})$ for $b / R=0.2$ 
Optimisation of the forced vibrations (in case the equilibrium position is stable) as well as the experimental investigations are consider as the next step towards implementation of this type of active bearing to control vibrations of rotor-bearing system.

\section{NOMENCLATURE}

A

$\boldsymbol{a}=\left[a_{x}, a_{y}\right]$

$a_{x}, a_{y}$

$B$

$b$

$\boldsymbol{C}_{s}=\left[C_{I_{s}}, C_{2 s}, C_{3 s}\right]$ - vector of the hydrodynamic

c - bearing radial clearance, $\mathrm{m}$

D - diameter of journal, $m$

d - diameter of the damper's

$\boldsymbol{F}_{r} \quad-$ vector of the external exci-

$\boldsymbol{H}_{s}=\left[H_{1 s}, H_{2 s}, H_{3 s}\right]-$ vector the hydrodynamic

$\boldsymbol{H}_{\boldsymbol{r}}=\left[H_{r x}, H_{r y}\right] \quad$ - vector of the hydrodynamic

$h(\varphi, t)$

$\boldsymbol{K}_{r}$

$k_{l}=B / V$

$k_{2}=\pi d^{4} / 128 \eta l$

$L$

- length of the journal bearforces acting on the flexible sleeve due to the chamber pressure, $\mathrm{N}$ capillary, $\mathrm{m}$ tation acting on journal along coordinates $x y, \mathrm{~N}$ forces acting on the flexible sleeve due to the oil film pressure, $\mathrm{N}$ forces acting on the journal due to the oil film pressure, $\mathrm{N}$

$L_{s}$

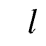

$\boldsymbol{M}_{r}$

$m$

$p_{n i}$

$p$

$P_{c a v}$

$p_{c}$

$Q$

$Q_{r}$

$\boldsymbol{q}=\left[q_{x}, q_{y}\right]$

$\dot{\boldsymbol{q}}$

$\boldsymbol{r}=\left[r_{1}, r_{2}, r_{3}\right]$

$R$

$s$

$S$

$t$

V

$V_{O}$

$\Delta V$

- instantaneous thickness of the oil film, $m$

- matrix of stiffness of the rotor, $\mathrm{N} / \mathrm{m}$

- coefficient of the oil compresibility, $\mathrm{Nm}^{-5}$

- throttling coefficient, $\mathrm{N}^{-1} \mathrm{~m}^{5} \mathrm{~s}^{-1}$

$d V_{c} / d t$

$W_{s}$

$\boldsymbol{w}=[x, y]$
- length of the flexble sleeve, $\mathrm{m}$

- length of the damper's capillary, $\mathrm{m}$

- matrix of inertia of the rotor, $\mathrm{kg}$

- weight of rotor, $\mathrm{kg}$

- input pressure, $\mathrm{Pa}$

- the oil film pressure, $\mathrm{Pa}$

- cavitation threshold, Pa

- the chamber pressure, Pa

- rate of flow, $\mathrm{m}^{3} / \mathrm{s}$

- vector of the static load acting on journal along coordinates $x y, \mathrm{~N}$

- vector of the relative coordinates of journal with respect to the centre of bearing

- vector of the relative velocities of journal with respect to bearing, $\mathrm{m} / \mathrm{s}$

- vector of the absolute position of the flexible sleeve, $\mathrm{m}$

- radius of journal, $m$

- length of the flexible sleeve associated with coordinate $\varphi, \mathrm{m}$

- span of rotor, $\mathrm{m}$

- time, s

- instantaneous volume of the chamber, $\mathrm{m}^{3}$

- initial volume of the chamber, $\mathrm{m}^{3}$

- fluctuation of the chamber volume due to motion of the flexible sleeve, $\mathrm{m}^{3}$

- rate of change of volume due to the oil compresibility, $\mathrm{m}^{3} / \mathrm{s}$

- width of the flexible sleeve, $\mathrm{m}$

- vector of the absolute coordinates of journal ing, $\mathrm{m}$ 
$x y z$

$x, y$

$\beta, \psi$

$\varphi$

$\omega_{1}$

$\Omega$

$\Omega$
- the absolute system of coordinates

- coordinates of the journal, $\mathrm{m}$

- angles defined in Fig. 5, rad

- angular coordinates defined in Fig. 2, rad

- first natural frequency of the rotor supported on the ball bearings only.

- angular velocity of the rotor, $\mathrm{rad} / \mathrm{s}$

\section{References}

Adams M. L., 1980. Non-Linear Dynamics of Flexible Multi-Bearing Rotors, Journal of Sound and Vibration, Vol. 71(1), pp. 129144.

Adams M. L. and McCloskey T. H., 1990. A Feasibility and Technology Assessment for the Implementation of Active Rotor Vibration Control Systems in Power Plant Rotating Machinery, Proceedings of 3rd International Conference on Rotordynamics, Lyon, pp. 327-332.

Althaus J., Ulbrich H. and Jäger T., 1990. Active Chamber System for Control of Rotor Dynamics, Theory and Experiment, Proceedings of 3rd International Conference on Rotordynamics, Lyon, pp. 333-338.

Ding, J. and Krodkiewski, J. M., 1993. Inclusion of Static Indetermination In The Mathematical Model For Non-Linear Dynamic

Analyses Of Multi-Bearing Rotor System, Journal of Sound and Vibration, Vol. 164(2), pp. 267-280.

Goodwin M. J., Boroomand T. and Hooke C. J., 1989. Variable Impedance Hydrodynamic Journal Bearings for Controlling Flexible Rotor Vibrations, The 1989 ASME Design Technology Conferences, Mechanical Vibration and Noise, Montreal, pp. 261-267.

Guyan, R. J., 1965. Reduction of Stiffness and Mass Matrices, American Institute of Aeronautics and Astronautics Journal, Vol. 3, No. 2, pp. 380-385.

Holmes A. G., Ettles C. M. McC. and Mayes I. W., 1978. The Dynamics of Multi-Rotor Systems Supported on Oil Film Bearings, Journal of Mechanical Design, Transaction of the ASME, Vol. 100, pp. 156-164.

Hori Y. and Uematsu R, 1980. Influence of Misalignment of Support Journal Bearings on Stability of a Multi-Rotor System, Tribology International, pp. 249-252.

Krodkiewski J. M., Sun L., 1995. Stability Control of Rotor-Bearing System by An Active Journal Bearing, Proc. of the International Conference on Vibration and Noise, Venice, pp. 217-225.

Lund, J. W., 1974. Stability And Damped Critical Speeds of A Flexible Rotor In Fluid-Film Bearings, Journal of Engineering for Industry, Transaction of the ASME, pp. 509-517.

Parszewski Z. A. and Krodkiewski M. J., 1986. Machine Dynamics In Terms of The System Configuration Parameters, Proceedings of the International Conference of Rotordynamics, Tokyo, pp. 239-244.

Parszewski Z. A. and Li D. X., 1989. Dynamically Optimum Configuration For A Multi-Bearing Rotor System-Theory And Experiments, Proceedings Of The International Symposium On Advanced Computers For Dynamics And Design '89, pp. 279-284.

Ulbrich H. and Althaus J., 1989. Actuator Design for Rotor Control, The 1989 ASME Design Technical Conferences, Mechanical Vibration and Noise, Montreal, pp. 17-22. 


\section{ait \\ ENERGY MATERIALS}

M A N E Y publishing

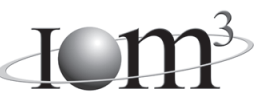

\section{Materials Science \& Engineering for Energy Systems}

Maney Publishing on behalf of the Institute of Materials, Minerals and Mining

The Institute of Materials, Minerals \& Mining

Economic and environmental factors are creating ever greater pressures for the efficient generation, transmission and use of energy. Materials developments are crucial to progress in all these areas: to innovation in design; to extending lifetime and maintenance intervals; and to successful operation in more demanding environments. Drawing together the broad community with interests in these areas, Energy Materials addresses materials needs in future energy generation, transmission, utilisation, conservation and storage. The journal covers thermal generation and gas turbines; renewable power (wind, wave, tidal, hydro, solar and geothermal); fuel cells (low and high temperature); materials issues relevant to biomass and biotechnology; nuclear power generation (fission and fusion); hydrogen generation and storage in the context of the 'hydrogen economy'; and the transmission and storage of the energy produced.

As well as publishing high-quality peer-reviewed research, Energy Materials promotes discussion of issues common to all sectors, through commissioned reviews and commentaries. The journal includes coverage of energy economics and policy, and broader social issues, since the political and legislative context influence research and investment decisions.

\section{CALL FOR PAPERS}

Contributions to the journal should be submitted online at http://ema.edmgr.com

To view the Notes for Contributors please visit: www.maney.co.uk/journals/notes/ema

Upon publication in 2006, this journal will be available via the Ingenta Connect journals service. To view free sample content online visit: www.ingentaconnect.com/content/maney

For further information please contact:

Maney Publishing UK

Tel: +44 (0)113 2497481 Fax: +44 (0)1132486983 Email: subscriptions@maney.co.uk

or

Maney Publishing North America

Tel (toll free): 8662975154 Fax: 6173546875 Email: maney@maneyusa.com

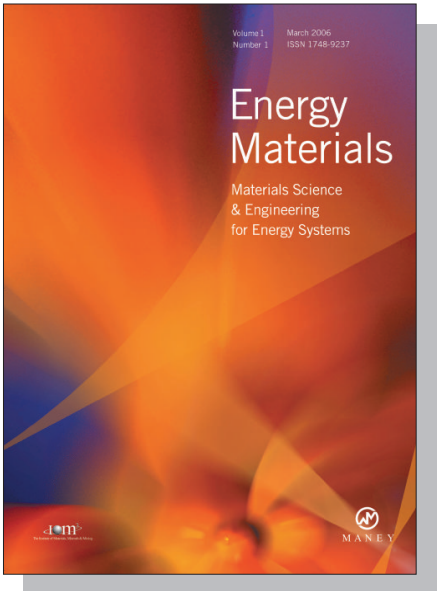

EDITORS

Dr Fujio Abe

NIMS, Japan

Dr John Hald, IPL-MPT, Technical University of Denmark, Denmark

Dr R Viswanathan, EPRI, USA

\section{SUBSCRIPTION INFORMATION}

Volume 1 (2006), 4 issues per year

Print ISSN: 1748-9237 Online ISSN: 1748-9245

Individual rate: $£ 76.00 / U S \$ 141.00$

Institutional rate: $£ 235.00 /$ US $\$ 435.00$

Online-only institutional rate: $£ 199.00 / U S \$ 367.00$

For special $\mathrm{IOM}^{3}$ member rates please email

subscriptions@maney.co.uk

\section{For further information or to subscribe online please visit www.maney.co.uk}



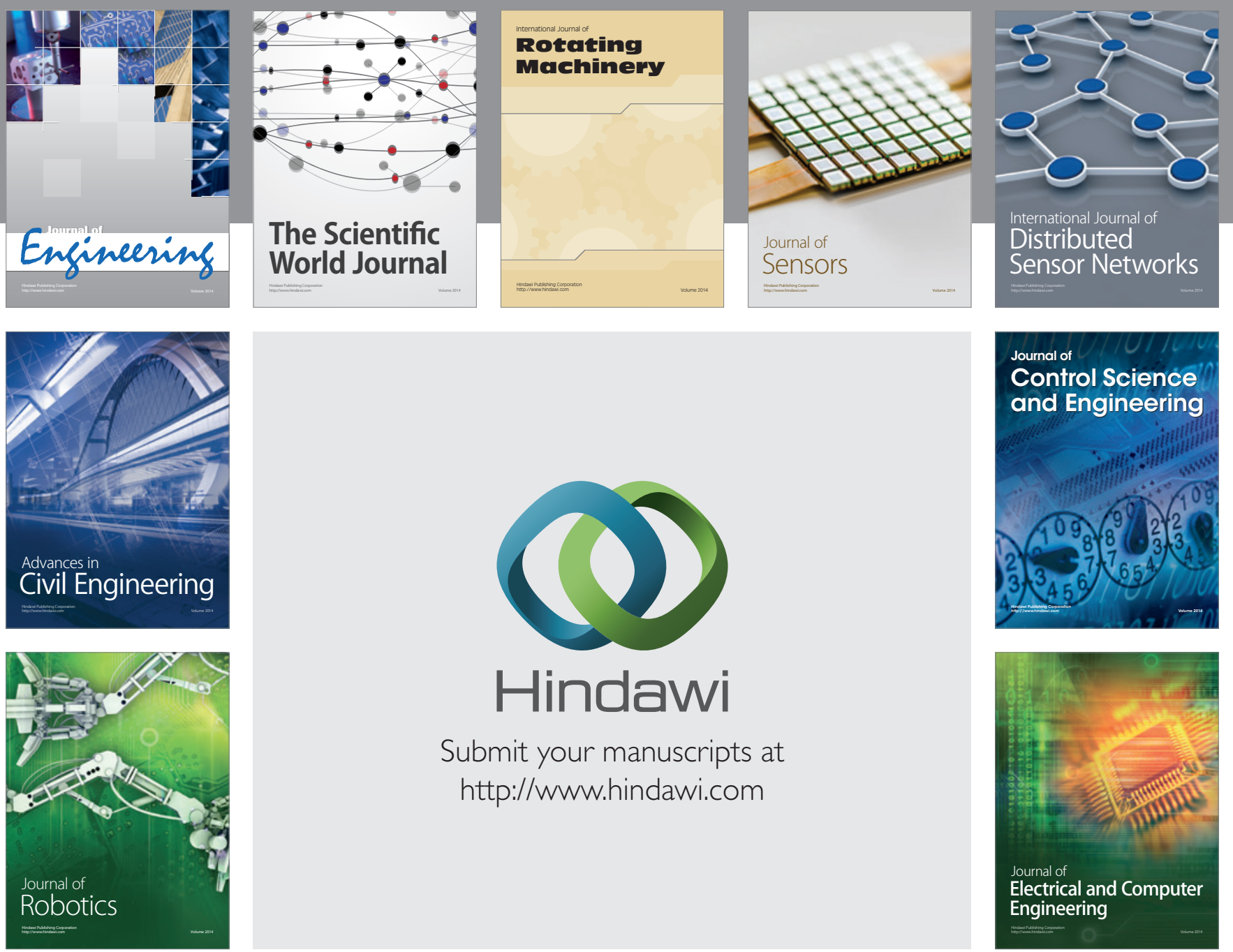

Submit your manuscripts at

http://www.hindawi.com
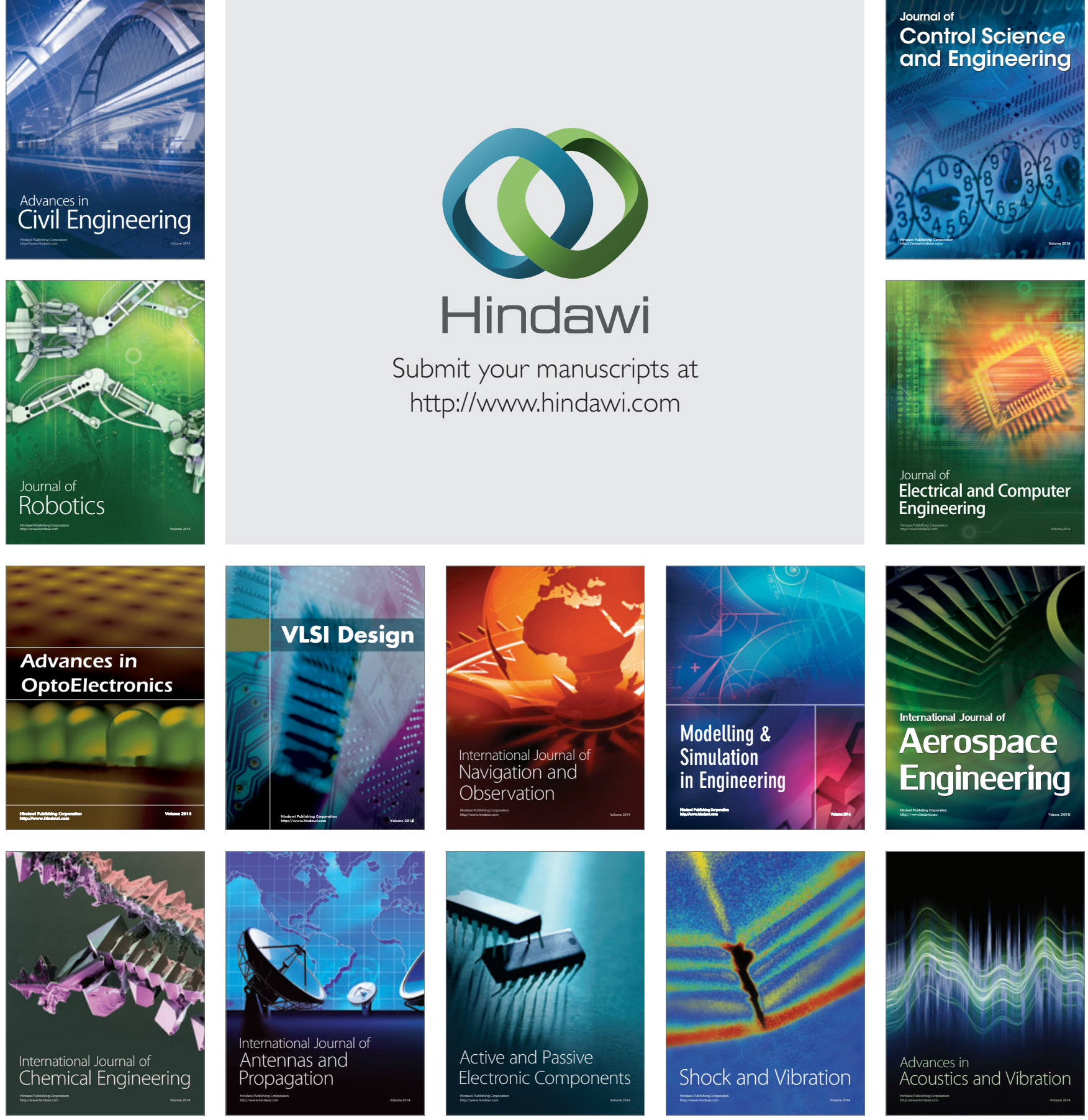